\title{
Correction to: An EBSD Evaluation of the Microstructure of Crept Nimonic 101 for the Validation of a Polycrystal-Plasticity Model
}

\author{
S. Reschka, L. Munk, P. Wriggers, and H.J. Maier
}

\section{Correction to:}

JMEPEG (2017) 26:6087-6098

https://doi.org/10.1007/s11665-017-3046-3

1. Missing pull-back

Equation 3 requires an additional pull-back of the basis vectors from the isoclinic intermediate configuration into the

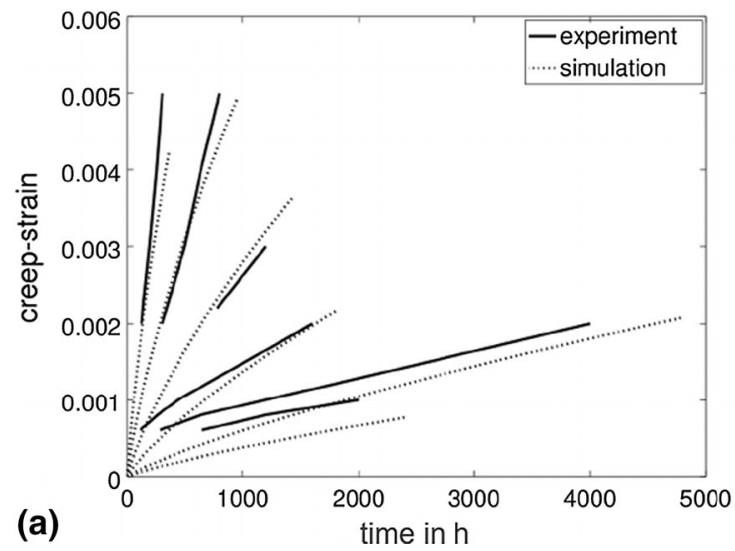

reference configuration. Thus, $C\left[\boldsymbol{E}_{e}\right]$ needs to be pre- and postmultiplied by $\boldsymbol{P}$. The corrected equation reads:

$\boldsymbol{S}=\boldsymbol{P C}\left[\boldsymbol{E}_{e}\right] \boldsymbol{P}^{\mathrm{T}}$.

All simulations were recomputed and the results are shown in the following.

2. Incorrect boundary condition in simulation example

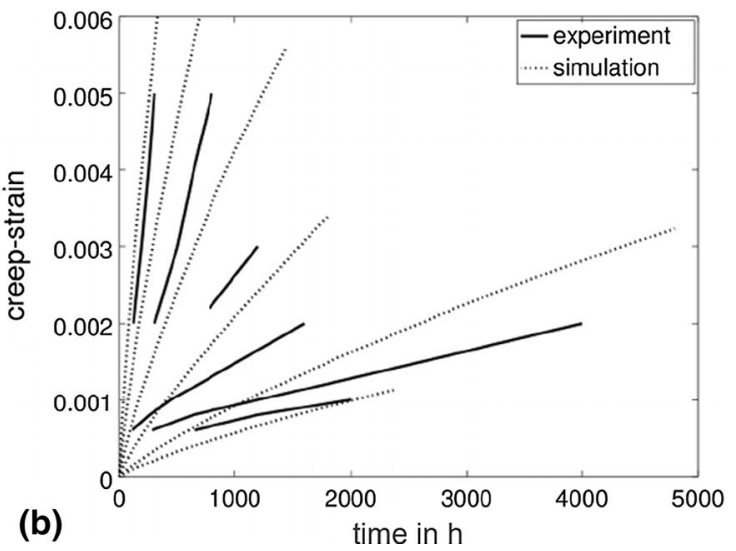

Fig. 6 Parameter fit to experimental data created using the values obtained by Borzdyka and Gecov (Ref 41 ) of Nimonic 90 with (a) pseudopolycrystal and (b) resulting behavior of a Voronoi-tesselated polycrystal

The original article can be found online at https://doi.org/10.1007/ s11665-017-3046-3.

S. Reschka and H.J. Maier, Institut für Werkstoffkunde, Leibniz Universität Hannover, Garbsen, Germany; and L. Munk and P. Wriggers, Institut für Kontinuumsmechanik, Leibniz Universität Hannover, Hannover, Germany. Contact e-mail: reschka@iw.unihannover.de. 


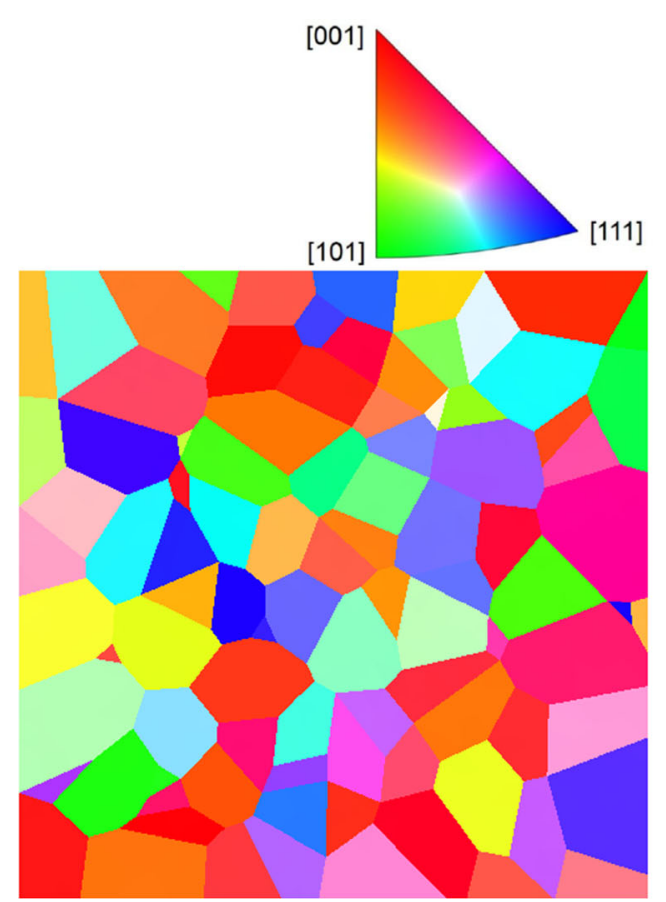

(a)

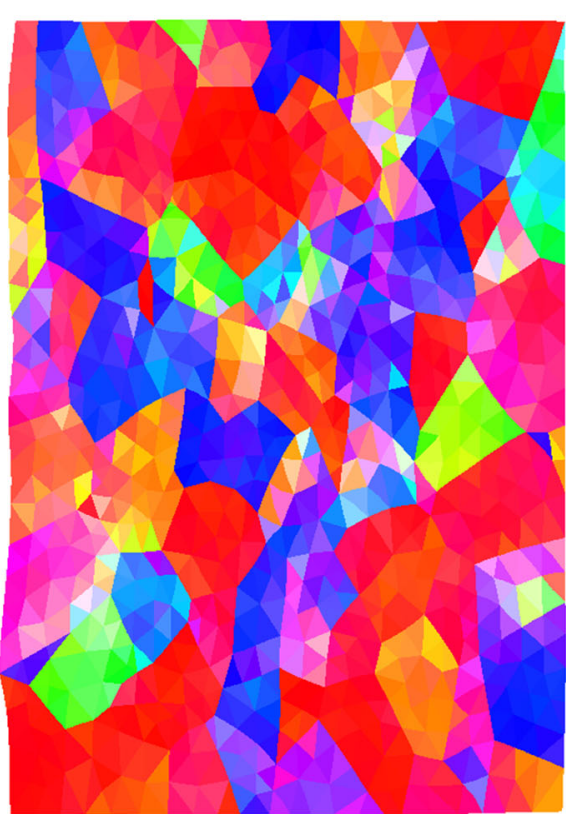

(b)

Fig. 13 Numerically obtained inverse pole figures of a 1000-grain Voronoi-tesselated polycrystal showing the grain orientation along the load axis (a) of the initial state and (b) after deformation to $27 \%$ over $17 \mathrm{~h}$

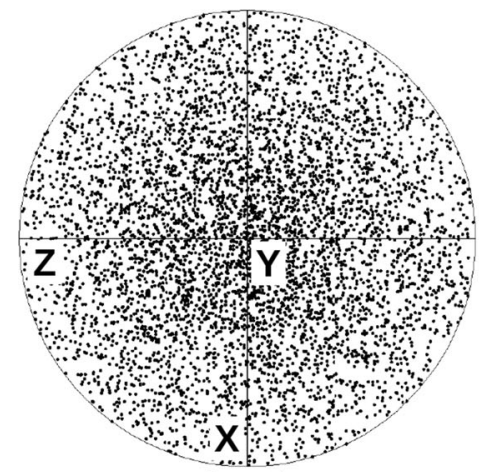

$\{110\}$

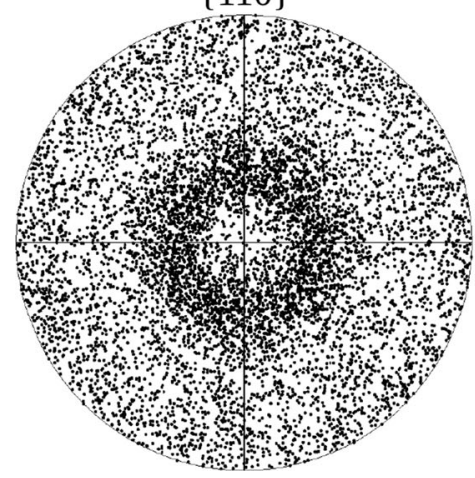

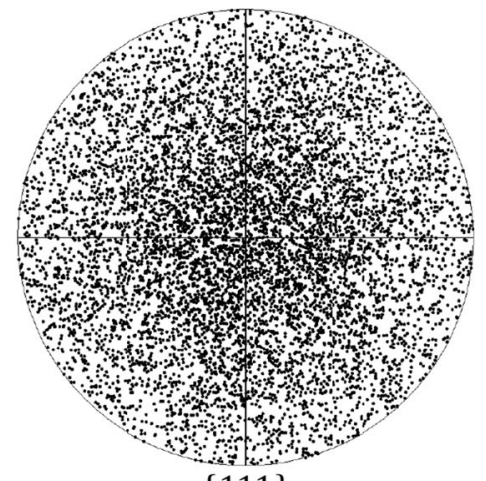

$\{111\}$

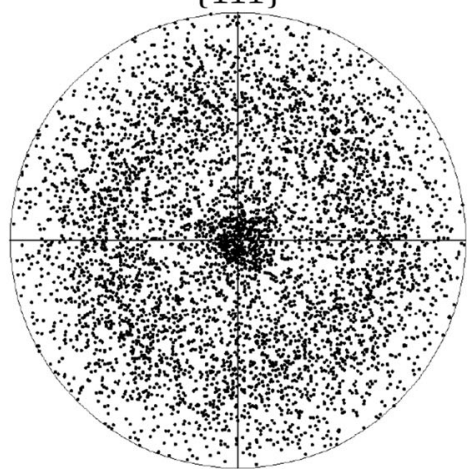

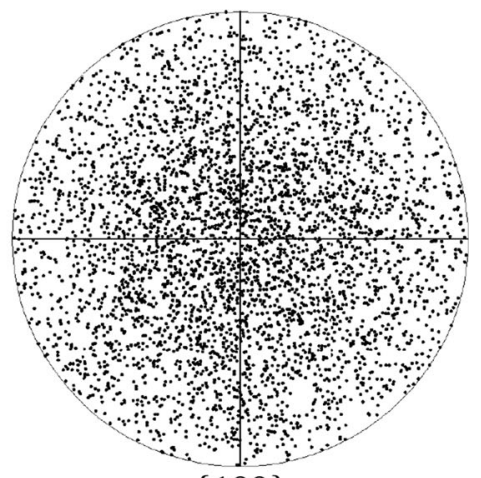

$\{100\}$

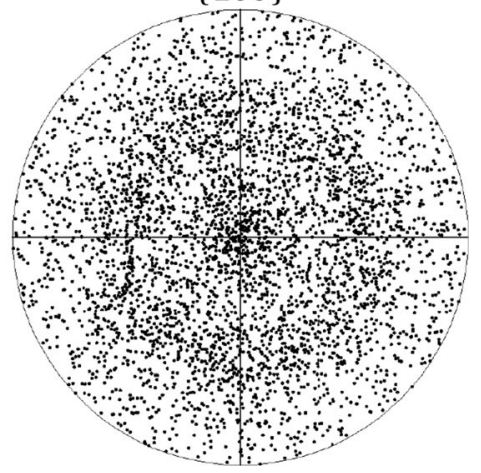

Fig. 14 Normal vectors $n_{E}=F_{e}^{-\mathrm{T}} n_{0}$ of specific type in the initial (first row) and current configuration (second row); eight random Voronoitesselated microstructures with 140 grains each were used to obtain the combined data. Direction of load axis is indicated by $y$

The simulation whose results are shown in Fig. 13 was incorrectly set up. The displacement boundary condition is now correctly prescribed; the final strain amounts to $27 \%$.
Publisher's Note Springer Nature remains neutral with regard to jurisdictional claims in published maps and institutional affiliations. 